\title{
Simulation Assisted Energy Optimization of Abandoned Agricultural Facilities: An Adaptive Reuse Approach
}

\author{
Rudina Breçani ${ }^{1}$, Rudina Belba ${ }^{1}$, Sokol Dervishi ${ }^{1}$ \\ ${ }^{1}$ Epoka University, Tirana, Albania
}

\begin{abstract}
This paper explores the energy performance and thermal comfort conditions of selected agricultural structures in three climatic regions in Albania. Computational simulation is used to analyse the performance and predict the consequences of alternative thermal retrofit measures. The study attempts a new approach to agricultural product preservation whilst minimizing the impact on landscape. The research provides an objective assessment of the actual thermal performance of the selected buildings. The alternative scenarios incorporate the use of thermal insulation of the walls and change of building geometry. The results suggest that changes of building morphology could reduce the annual energy consumption up to $25 \%$.
\end{abstract}

\section{Introduction}

Climate change, the limited availability of productive land, and the draining stress placed on natural resources are some of the challenges the food industry is facing, while at the same time trying to meet the rising population's demand. By 2030 it is expected that population expansion and economic growth will increase the global demand for energy and water by 40 percent and the demand for food will increase by 50 percent, to be met primarily through yield increases (Energy smart foods, 2011).

Investing in agriculture is an effective strategy for reducing poverty, inequality, and hunger (FAO, 2011). Food conservation is a delicate topic, significant to human health. The food market should attempt to reach sustainability since the global food sector is dependent on energy inputs (FAO, 2011). As such, there is a need for preservation models against food waste.

Transformative processes towards 'holistic' approaches including climate-smart agriculture and conservation agriculture are needed towards indigenous and traditional knowledge (FAO, 2011).

Furthermore, the optimization of agricultural land is vital in times when the phenomenon of informal occupation resulting in degradation of land has become so frequent. As this is a global issue, although this scientific research focuses on a particular case study and context, the methods applied are universal and applicable to other contexts.

Likewise, the scientific research on optimization of agricultural produce in an affordable way is extremely limited. This study proposes an energy model, with respect to climate and with a primary objective of preservation.

There exists some, albeit punctual and limited, research on estimation of the energy required for preserving foods in their respective ideal thermal conditions. Lamidi et al. (2019) have concluded conventional solar drying for agricultural produce has some drawbacks, opting for renewable energy instead which results in a more affordable economic rate. The demand for additive-free, extended shelf-life food products, with fresh-like tastes, excellent nutritional quality and guaranteed microbial safety, has led to the development of innovative processing and preservation technologies (Atuonwu et al, 2018).

Colak (2007) states that energy analyses can reveal the possibility to design more efficient thermal systems for olive oil production. Other researchers, such as Berroug (2011), have investigated the use of alternative heating systems for greenhouses, examining both humidity values and choice of materials. Torres Jara et al (2018) have analysed the thermal behaviour of a refrigerated vehicle for food transport. Song et al (2018) have examined food temperature models for eggs and milk to predict food temperature changes during distribution.

This study will focus instead on the adaptation of existing facilities as food storage units and the estimation of their energy efficiency. These facilities will be observed in Albania, a country in South-Eastern Europe, which has historically relied economically on agriculture.

Nowadays, the Albanian government finds itself in the right position to seek and test energy efficient ways to store and harvest agricultural produce for its country (NTPA, 2016). Historically, agriculture has been the main economic branch in Albania, from the large-scale state owned cooperatives during socialism to family supporting private farms in present days.

The year 1990 signed the fall of the socialist regime in Albania, and whilst it was a great chance for individual freedom, it backfired in terms of urban spatial planning. The previously state-owned land was redistributed among individuals who had a claim on them, or among the people who had worked in the creation of agricultural land during the regime. Nevertheless, this newfound freedom ended up damaging the overall land and territory since it lacked an overall guidance.

About a quarter of Albania is officially recorded as farmland: the arable, low-lying lands along the coast. The 
productivity of this area is decreasing due to informal, uncontrolled construction on agricultural land, which threatens both the acreage and its productivity. Important products are vegetables, potatoes, olives, citrus and other orchard fruits, grapes and, increasingly, in the mountainous areas, herbs. In the mountainous areas, many farmers live a marginal existence. They merely produce their own food. The distribution network is highly informal, consisting of farmers offering their produce at markets and in the streets of towns and villages. They face competition by supermarkets that in many cases buy their products abroad (iabr / UP et al, 2016).

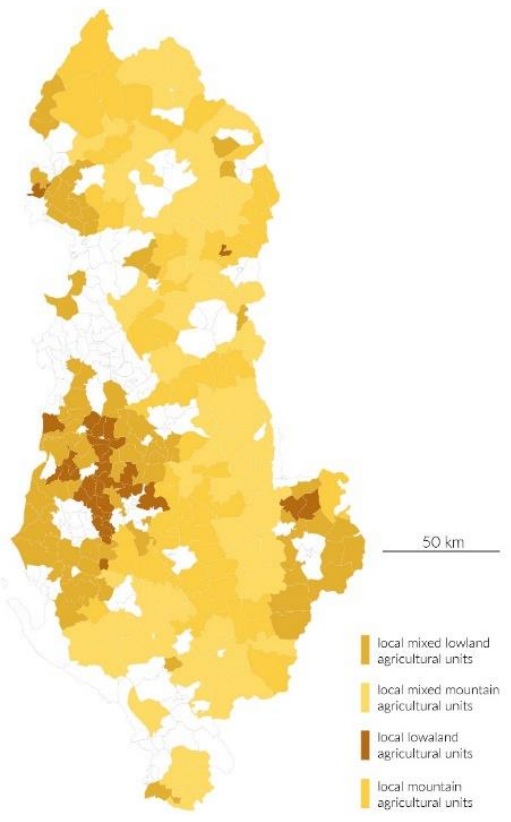

Figure 1: Illustration on the agricultural inclination of the Albanian territory.

The Metabolism of Albania states that export is remarkably weak: more food is wasted than exported. Nevertheless, the country finds in the right position to successfully address and overcome its issues in regards of agricultural produce.

With the newest governmental reform of the rural development of 100 villages with focus on agro tourism, there is plenty of attention and potential investment concentration on related topics.

There is a large amount of abandoned, unfinished, or ruined structures throughout the Albanian territory. A large amount of them is facilities, which served as warehouses during the socialist regime. These modular structures are extensively common in Albania, in rural or industrial context.

In such an important gap in the research for sustainable and affordable agriculture, this study focuses on the combined optimization of various factors during energy assessment. Furthermore, the novelty of this research ties to the attempt at optimizing agricultural land, increasing agricultural product preservation, and minimizing of landscape alteration simultaneously.

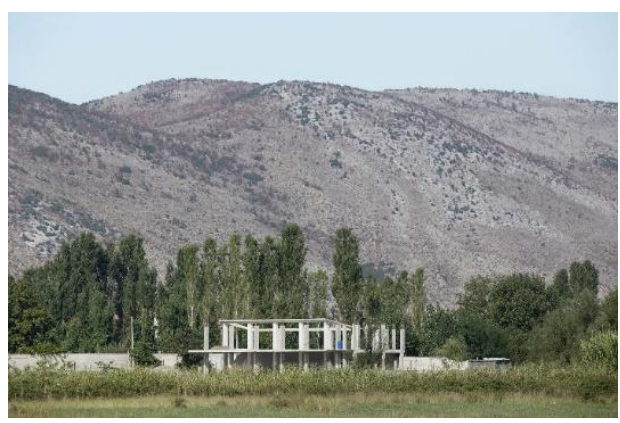

Figure 2: Example of informal land occupation (NTPA, 2016).

The simulations examine and evaluate the potential of energy consumption reduction for these abandoned facilities vastly found throughout the country undergoing adaptive reuse design through a multi-disciplinary approach. Furthermore, the study relies on on-site observations, participatory planning, and respect to local traditional construction techniques and collective memory in order to assess the best-case scenario for development of these abandoned facilities.

Concerning a broad and current interest, the study's relevance is related to the creation of a sustainable pilot research, which may be considered for real life implementation firstly in the villages included in the agricultural renewal reform currently in process in Albania, and further in a larger scale.

\section{Methodology}

The purpose of this study is to explore the thermal and energy performance of the commonly used agricultural structure in Albania. The objective is to attain the preservation of the agricultural products based on different climates, and evaluate the necessary scenarios in order to achieve the performance with the least amount of energy consumption.

The software used to conduct simulations is Design Builder, an Energy Plus simulation software used to predict building thermal and energy behaviour by allowing the user to specify variables such as building materials, geographic location, activity held, occupancy density etc.

In the present paper, a modular structure used as warehouse for agricultural produce is chosen to conduct simulations and develop possible scenarios for adaptive reuse. Simultaneously, the three main domestically cultivated products are considered in order to determine the temperature threshold, as well as the outdoor climate. The structure used for the simulations, as shown in Figure 3 , is a modular high pitched longitudinal brick building of one story. Such modular structures are widely present in Albania, in rural and industrial contexts, and their restoration and adaptive reuse is not only economic and feasible, but may trigger small-scale agricultural revitalization 

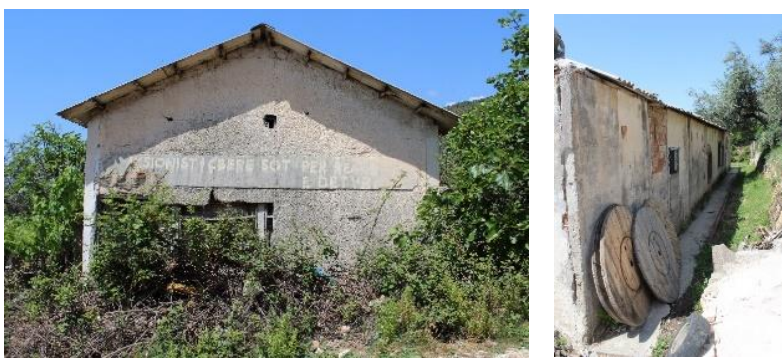

Figure 3: Existing modular structure present in Southern Albania (NTPA, 2018).

The products chosen for the study (olives, apples and potatoes) are the top three most produced foods in Albania, thus determining also the climates chosen for the comparative simulations in accordance to the regions where they are most largely produced, Fier, Korca, and Shkodra respectively. Figure 5 illustrates the highest and lowest yearly outdoor temperatures for the cities. For the simulations, weather data gathered from the Meteonorm software for the Albanian cities of Fier, Shkodra, and Korça were used.

The preservation conditions for the foods is explored including the preservation temperature $\left({ }^{\circ} \mathrm{C}\right)$, relative humidity (\%), approximate storage life of selected produce (see Table 1). Suggestions pertaining the structure's geometry change in order to reduce energy consumption for the purpose of food preservation are given for each climate (see Table 2). Five scenarios are defined for each climate/product to define energy consumption for the existing structure and for the proposed changes including building materials and activity. In a previous study by Brecani and Dervishi (2019), underground facilities are depicted as able to preserve cool indoor temperatures during summer. This is due to the low heat conductivity of the soil, in which the heat flux is practically constant and follows Equation 1. This fact is taken into consideration during changes on the structure's geometry.

$$
q=-k \frac{\partial T}{\partial x}
$$

The most determining factor in the longevity of the agricultural produce is the temperature of the ambience that serves as a storage. Storage capacity, energy/area consumption rate, area in contact with the earth, and climate are taken in consideration in order to determine the scenarios.

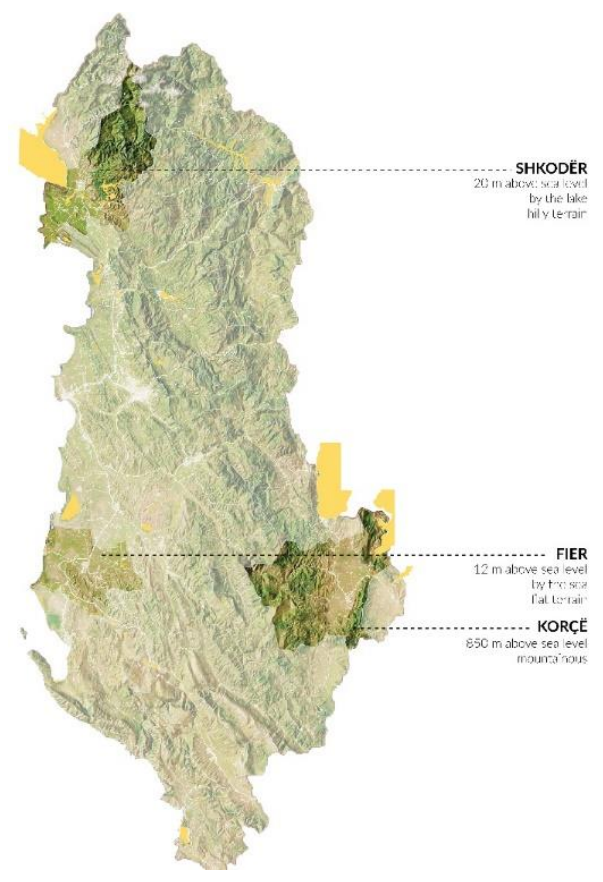

Figure 4: Location of the three climatic zones chosen for the simulation scenarios.

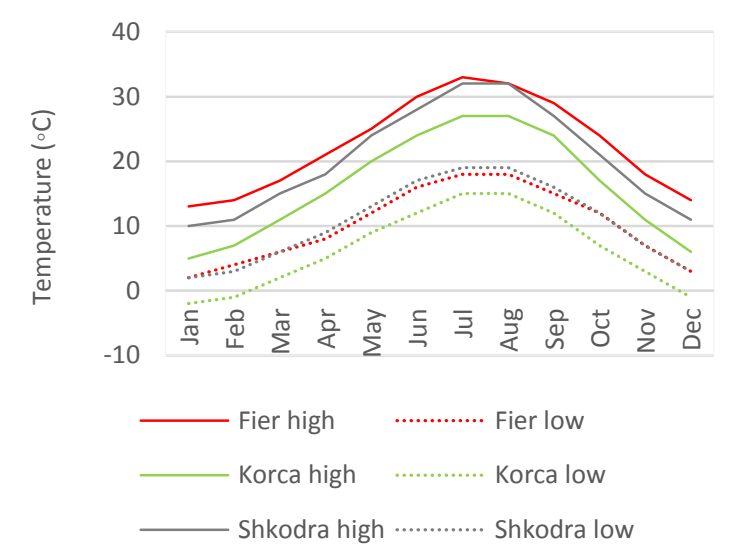

Figure 5: Highest and lowest yearly outdoor temperatures for the cities of Fier, Korca, and Shkodra.

Table 1. Data pertaining to location, altitude above sea level (m), agricultural produce, preservation temperature $\left({ }^{\circ} \mathrm{C}\right)$, relative humidity (\%), approximate storage life of selected produce, and scenario code where they are applied.

\begin{tabular}{cccccc}
\hline Location & Altitude & Product & Temperature $\left({ }^{\circ} \mathbf{C}\right)$ & $\begin{array}{c}\text { Relative humidity } \\
(\mathbf{\%})\end{array}$ & $\begin{array}{c}\text { Approximate } \\
\text { storage life }\end{array}$ \\
\hline Fier & $\begin{array}{c}20 \mathrm{~m} \text { above sea } \\
\text { level }\end{array}$ & Olives & $5-10$ & $90-95$ & $4-6$ months \\
\hline Korca & $\begin{array}{c}850 \mathrm{~m} \text { above sea } \\
\text { level }\end{array}$ & Apples & $-1.1-4.4$ & $90-95$ & $1-12$ months \\
\hline Shkodra & $\begin{array}{c}\text { m above sea } \\
\text { level }\end{array}$ & Potatoes & $\begin{array}{c}3.3-4.4(\text { early } \\
\text { crop }) \\
4.4 \\
\text { (late crop })\end{array}$ & $\begin{array}{c}4-5 \text { months } \\
\text { (early crop) } \\
5-10 \text { months } \\
\text { (late crop) }\end{array}$ \\
\hline
\end{tabular}


Table 2: Description of the simulation scenarios (SFO-SF4, SKO-SK4, and SSO-SS4) with associated U-value assumptions regarding the pertinent building components.

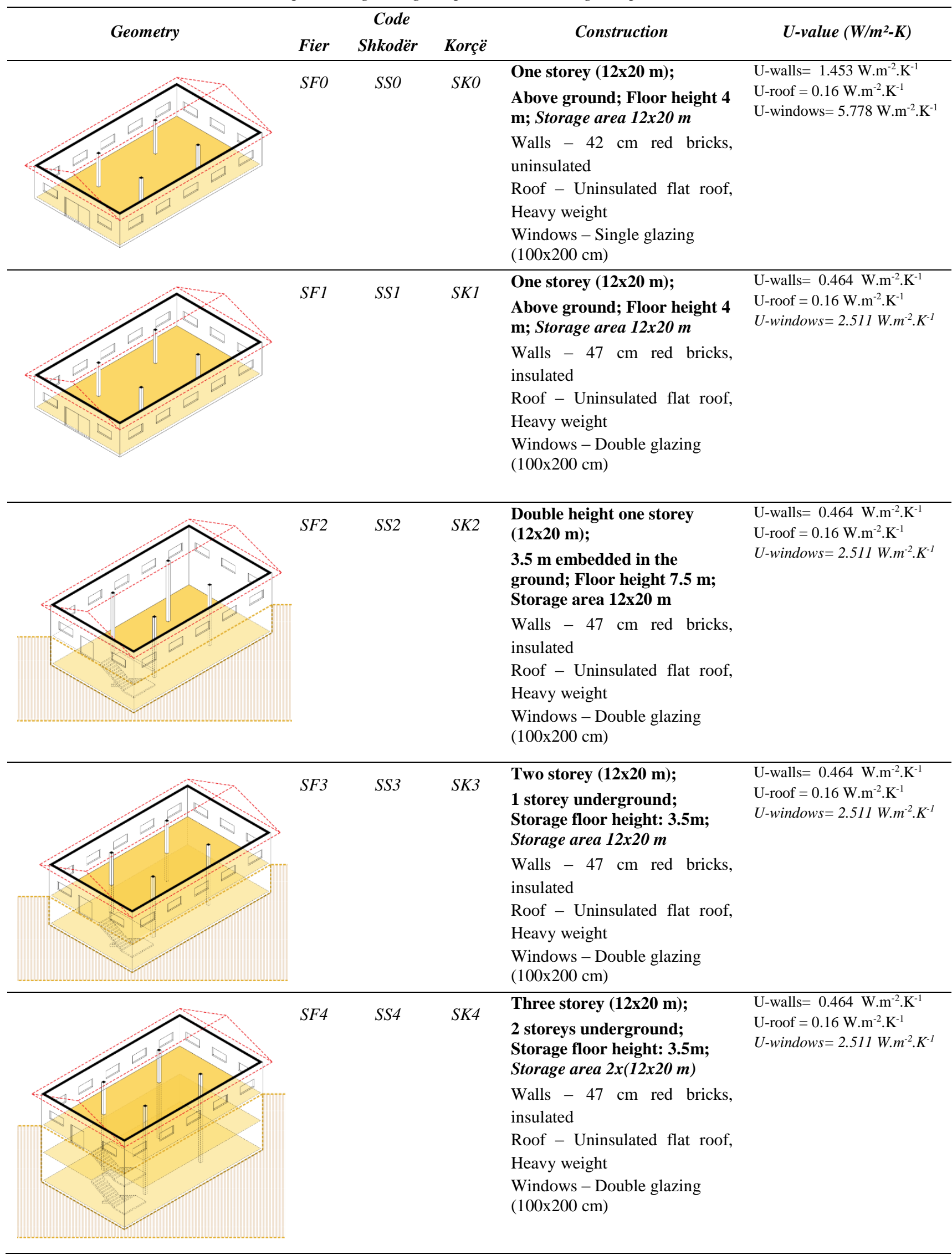


The existing condition serves as the base case scenario for all three climates, SF0, SS0, and SK0. An improved version of the existing condition (with wall insulation and double-glazing instead of single glazing) serves as the first improvement scenario, SF1, SS1, and SK1. These scenarios serve as the base for the other improvement scenarios, which propose mainly changes in the overall geometry of the structure.

Considering the low heat conductivity of the earth (Breçani and Dervishi, 2019), as well as the concern to diminish the landscape intrusions, the additional changes propose an extension of the structure underground. Scenarios SF2, SS2, and SK2 are double height structures partially embedded underground. Scenarios SF3, SS3, and SK3 are two storey structures, the same as scenarios SF1, SS1, and SK1 respectively, but with an additional storey underground. All these scenarios have a storage capacity of one floor, or $12 \times 20 \mathrm{~m}$, with scenarios SF3, $\mathrm{SS} 3$, and SK3 using the ground floor as a processing space.

A fifth scenario, SF4, SS4, and SK4, add an additional underground floor to the existing structure, 2 in total, and 3 storeys overall. The purpose of these last scenarios is mainly to determine whether there is a thermal performance change between storey -1 and -2 , and to increase storage capacity. For SF4, SS4, and SK4 the storage capacity is of two floors, or $2 \times(12 \times 20) \mathrm{m}$, whilst the ground floor is used as a processing space.

The energy consumption is not calculated for scenarios SF0, SS0, and SK0 due to it being in passive mode, with no occupancy, no HVAC implemented, and no activity. The thermal performance is calculated and depicted only for the structure's zones that serve the function of storage.

\section{Results and Discussion}

The results from the thermal and energy performance simulations of the modular structure are illustrated in Figures 6-11. Figures 6-7 illustrate the thermal performance of Base Case scenarios, with and without thermal insulation, for each climate zone. Figure 8 compares all the scenarios with thermal insulation for each climate during two reference days in January, whilst Figure 9 illustrates the same comparison for two reference days in July. Figures 10-11 show the monthly and annual energy consumption for the scenarios, for each climate.

Comparing the results from the different scenarios, the objective is to identify the best scenario which fits the preservation requirements of the products the closest, in terms of temperature, but which consumes the least amount of energy. According to data depicted in Table 1, the agricultural produce requires lower temperature in order for its preservation to last longer, hence in this occasion, the scenario that performs the lowest temperatures during both January and July is the preferred optimum.

Whilst the thermal performance of the uninsulated base case scenarios (SF0, SS0, and SK0) during January is higher than the insulated base case scenarios (SF1, SS1, and SK1), i.e. the temperatures are kept lower, during July it is much poorer, as illustrated in Figures 6-7. The difference in performance during January is of $3-5^{\circ} \mathrm{C}$, whilst during July the difference is of $12-15^{\circ} \mathrm{C}$. Since the thermal performance gap is much higher during July than it is during January, as a conclusion the insulated base case scenarios fit the scope of agricultural product preservation with a higher efficiency.

An important observation that results from the findings is that after reaching a certain temperature, the air temperature of the insulated base case scenarios (SF1, SS1, and SK1) cannot lower further without the implementation of artificial ventilation and air conditioning.

The differences in the indoor air temperature of the scenarios where changes in geometry are implemented, are then reflected in order to compare the thermal performance of each. The thermal performance is evaluated only for the spaces that are intended to be used as storage areas, as illustrated in Table 2. Additionally, to further assess the efficiency of each scenario, an overall monthly and annual energy consumption comparison is made. The annual energy consumption is evaluated for the entire building in comparison with the entire volume.

Results show that scenario SF4 consumes the most energy. This happens for two reasons: firstly, scenario SF4 has a higher volume when compared to the other scenarios that pertain to the same weather data, and secondly, because of the weather of Fier being warmer than that of Shkoder and Korca, the structure needs to consume more energy to keep the indoor temperature as low as the corresponding scenarios.

The scenarios that consume the least energy are SK1 and SK2, both located in the city of Korca, where outdoor temperatures are always lower that Shkoder and Fier. The energy consumption between these two scenarios has little difference, hence, taking in consideration also the thermal performance (Figures 8-9 show that temperatures in SK2 are lower than in SK1), we may conclude that the most efficient scenario overall is SK2.

Whilst an overall comparison of the scenarios considered for this study is feasible, it is crucial to understand that the modular structures are spread throughout the entire territory of Albania, thus there will be differences among the performance of the best-case scenarios for each city due to the climate characteristics.

Table 3 depicts the ranking of each scenario in terms of thermal and energy performance with 1 being the best case and 12 the worst regarding agricultural product preservation; the best overall scenario is highlighted in yellow, whilst the best scenarios for each city are highlighted in green, taking in consideration negligible differences in energy or thermal performance as well.

Results from Table 3 suggest that changes to the building morphology greatly affect the yearly energy consumption of the structure: the annual energy reduction resulting from differences in overall structure geometry fluctuate from $9-25 \%$. 


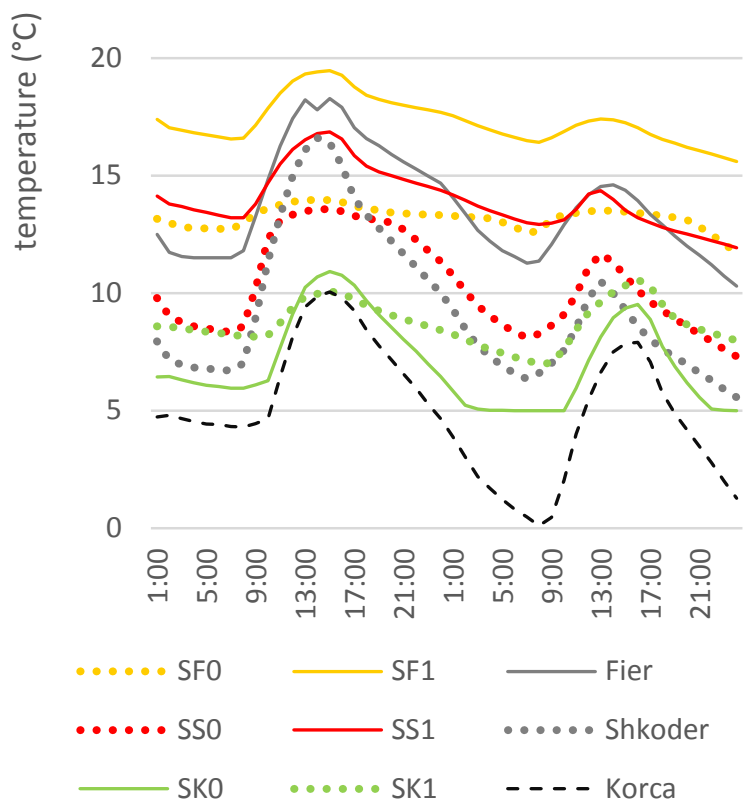

Figure 6: Simulated indoor temperatures (whole building) for SFO-SF1, SSO-SS1, and SKO-SK1, together with the external temperature data from the weather file of the respective cities (15th and 16th of January 2018).

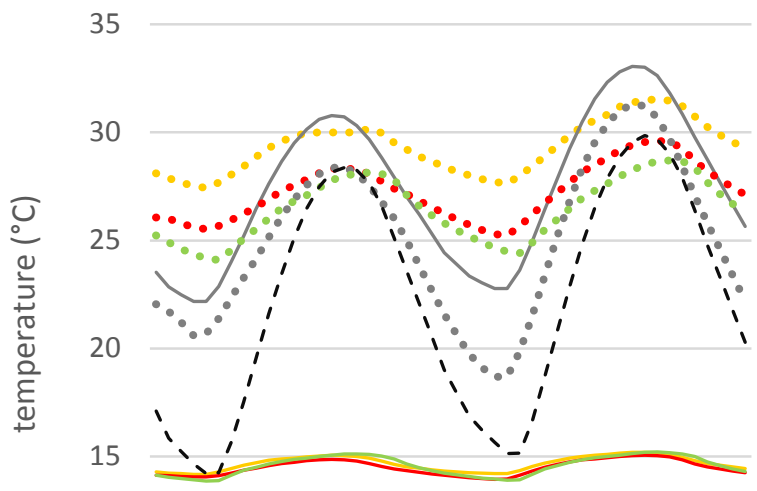

10

5
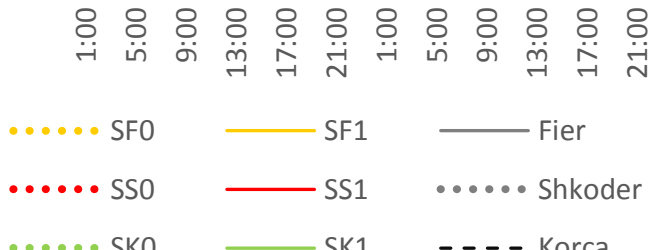

Figure 7: Simulated indoor temperatures (whole building) for SFO-SF1, SSO-SS1, and SKO-SK1, together with the external temperature data from the weather file of the respective cities (15th and 16th of July 2018).
25

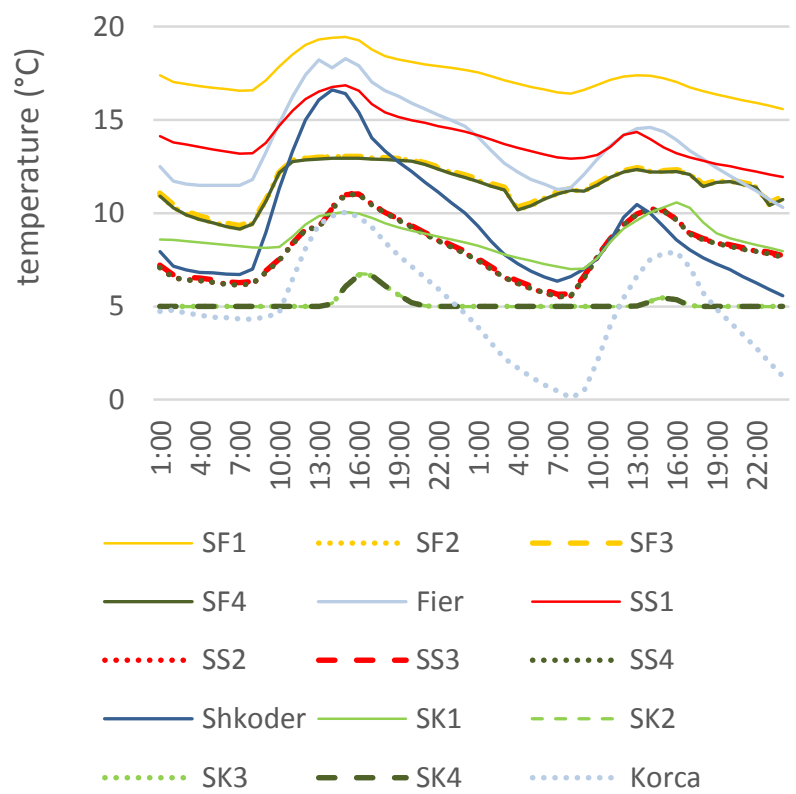

Figure 8: Comparison of the simulated indoor temperatures (whole building) of the activity scenarios SF1-SF4, SS1-SS4, and SK1-SK4 together with the external temperature data from the weather file of the respective cities (15th and 16th of January 2018).

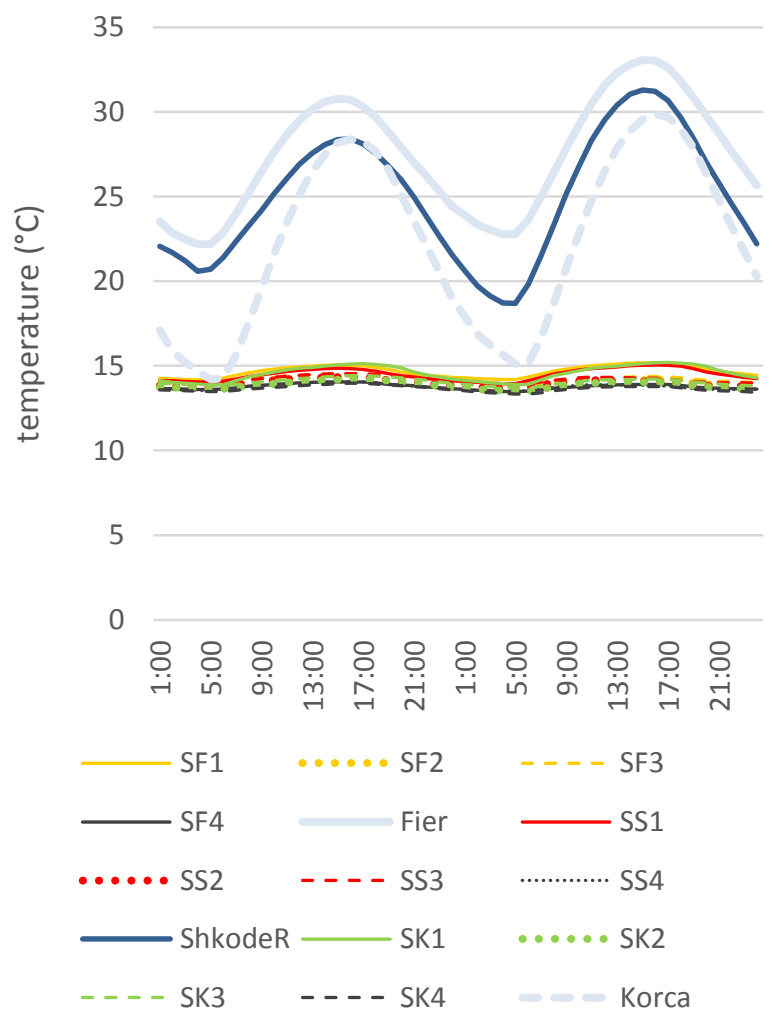

Figure 9: Comparison of the simulated indoor temperatures (whole building) of the activity scenarios SF1-SF4, SS1-SS4, and SK1-SK4 together with the external temperature data from the weather file of the respective cities (15th and 16th of July 2018). 


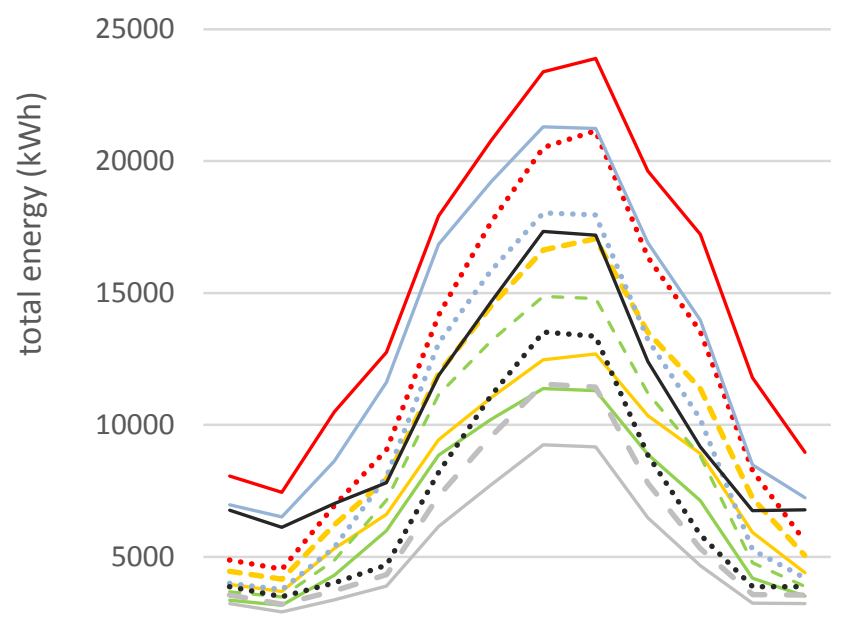

0

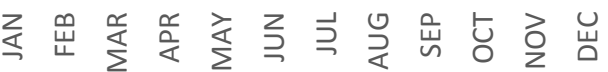

$$
\begin{aligned}
& \text { SF1 }-\ldots \text { SF2 - SF3 .........SF4 } \\
& \text { SS1 - - - SS2 - SS3 ........SSS } \\
& \text { SK1 - - -SK2 - SK3 …..... SK4 }
\end{aligned}
$$

Figure 10: Comparison of the total monthly energy consumption of the activity scenarios SF1-SF4, SS1-SS4, and SK1-SK4.

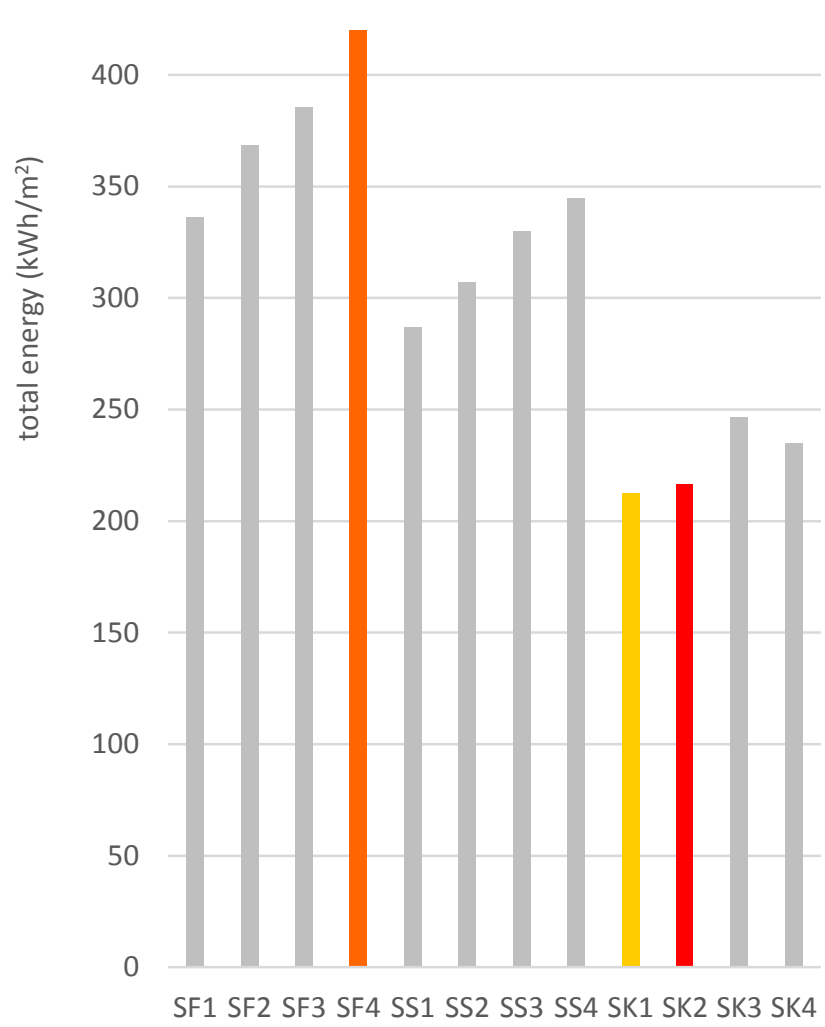

Figure 11: Comparison of the annual energy consumption per unit of the activity scenarios SF1-SF4, SS1-SS4, and SK1-SK4.

Table 3: Ranking of scenarios in terms of thermal and energy performance.

\begin{tabular}{cccccccccccccc}
\hline Scenario & SF1 & SF2 & SF3 & SF4 & SS1 & SS2 & SS3 & SS4 & SK1 & SK2 & SK3 & SK4 \\
\hline $\begin{array}{c}\text { Thermal } \\
\text { performance }\end{array}$ & 12 & 9 & 10 & 8 & 11 & 6 & 7 & 5 & 4 & 2 & 3 & 1 \\
& & & & & & & & & & & & & \\
Energy (yearly) & 8 & 10 & 11 & 12 & 5 & 6 & 7 & 9 & 1 & 2 & 4 & 3 \\
\hline
\end{tabular}

\section{Conclusion}

The present research study investigates the possibility of drafting a sustainable agricultural model for abandoned facilities undergoing adaptive reuse. The aim is to produce a replicable model that pertains satisfactory environmental and energy performance and which may be easily implemented in other environments of analogous conditions. The study aims to draft recommendations to which the variables should adhere in order to determine the sustainable agricultural model. The method is tested in buildings located in three Albanian regions, which vary in climate characteristics, geographic position, as well as agricultural produce potential. Different scenarios are tested pertaining to different variables such as building envelope, and structure geometry.

A modular agricultural warehouse structure was used for conducting thermal performance and energy consumption computer aided evaluation. The scenarios that were tested take in consideration the thermal preservation requirements of the three most locally produced agricultural products in Albania, each cultivated in a different climate zone.

The warehouse was proposed with some structural changes and was analysed in given form (one story structure), two-story structure half embedded in the ground, as a double height structure half embedded in the ground, and as a three storey structure with two storeys 
underground. In order to indicate the best scenario, firstly the temperature performances are compared. The preferred outcome of this comparison is the scenario that keeps the lowest temperatures, allowing a longer preservation period for the agricultural products stored in it. The second determining factor for the best-case scenarios is the annual energy/unit area consumption. These cases perform the lowest temperature with the least energy consumption. Moreover, there is a best-case scenario for each city, due to the different climate characteristics.

By analytically comparing the different scenarios, results show that the best cases are the double height scenarios, SF2, SS2, and SK2, whilst scenario SK4, three storey structure with 2 underground storage floors, achievers the largest storage capacity with the least energy consumption. The changes in building geometry affect the yearly energy consumption from $9-25 \%$.

\section{References}

Atuonwu, J.C., Leadley, C., Bosman, A., Tassou S.A, LopezQuiroga, E., and Fryer, P.J. (2018). Comparative assessment of innovative and conventional food preservation technologies: process energy performance and greenhouse gas emissions. To appear in Innovative Food Science and Emerging Technologies.

Berrouga, F., Lakhala, E.K., Omaria, E., Faraji, M., and Qarniac., H.E. (2011). Thermal performance of a greenhouse with a phase change material north wall. Energy and Buildings 43, 3027-3035.
Breçani, R. and Dervishi S. (2019). Thermal and Energy Performance Evaluation of Underground Bunkers: An Adaptive Reuse Approach. Sustainable Cities and Society 46.

Colak, N. and Hepbasli A. (2007). Performance analysis of drying of green olive in a tray dryer. Food Engineering 80, 1188-1193.

Food And Agriculture Organization Of The United Nations. Energy-Smart Food For People And Climate. Rome (Italy).

Iabr/UP, 51N4E, TU Delft, and NTPA (2016). The Metabolism of Albania. Tirana (Albania).

Lamidi, R.O., Jiang, L., Pathare, P.B., Wang, Y.D., and Roskilly, A.P. (2019). Recent advances in sustainable drying of agricultural produce: A review. Applied Energy 233-234, 367-385.

NTPA (2016). General National Spatial Plan. Tirana (Albania).

NTPA (2016). Evoked. Tirana (Albania).

Song, H., Kim, J., Kim, B.S., and Koo, J. (2018). Development of a food temperature prediction model for real time food quality assessment. To appear in International Journal of Refrigeration.

Torres Jara, P.B., Aguirre Rivera, J.J., Buenano Merino, C.E., Vazquez Silva, E., and Abad Farfan, G. (2018). Thermal behavior of a refrigerated vehicle: process simulation. International Journal of Refrigeration. 